\title{
Translation and psychometric evaluation of the Korean version of the fertility awareness and attitudes towards parenthood questionnaire
}

\author{
Hyewon Shin ${ }^{1}$, Minjoo Hong ${ }^{2}$, Minjeong Jo ${ }^{3}$, Jungmin Lee ${ }^{4}$ \\ ${ }^{1}$ Assistant Professor, College of Nursing, Ewha Womans University, Seoul; ${ }^{2}$ Assistant Professor, College of Nursing, Gyeongsang National University, Jinju; \\ ${ }^{3}$ Assistant Professor, College of Nursing, The Catholic University of Korea, Seoul; ${ }^{4}$ Lecturer, School of Nursing, Hallym University, Chuncheon, Korea
}

Purpose: This study presents a translation, cultural adaptation, and psychometric evaluation of two instruments of the Fertility Awareness and Attitudes Towards Parenthood (FAAP) questionnaire (Conditions and Life changes) for use in South Korea. Methods: This methodological study included 166 university students for psychometric evaluation in the sixth step. The first five steps included forward translation, backward translation, committee review, assessment of content validity, and a pre-test. In the sixth step, psychometric properties, including internal consistency, construct validity, and criterion validity, were evaluated. Exploratory factor analysis and confirmatory factor analysis were conducted to identify the structure of the tool and to assess its validity. Results: The Korean version showed acceptable internal consistency. Cronbach's $\alpha$ was .73 for FAAPConditions and .83 for FAAP-Life changes. FAAP-Conditions showed a four-factor structure (social conditions, relationship with partner, external environment, and child-rearing support) and FAAP-Life changes had a two-factor structure (reward and burden). In the confirmatory analysis, CMIN/DF, TLI, IFI, SRMR, CFI, and RMSEA were satisfactory. Conclusion: This study provided preliminary evidence of the acceptability, reliability, and validity of the Korean version of the FAAP questionnaire in university students in South Korea. Nonetheless, further evaluation among Korean young adults is warranted to validate this instrument.

Key words: Attitudes; Parenting; Validation studies; Young adults

\section{Corresponding author Minjeong Jo \\ College of Nursing, The Catholic University of Korea, 222 Banpo-daero, Seocho-gu, Seoul 06591, Korea \\ TEL: +82-2-2258-7412 \\ FAX: $+82-2-532-6537$ \\ E-MAIL: minjeongjo@catholic.ac.kr}

This study was presented as a poster abstract at the summer 2021 conference of the Korean Academy of Child Health Nursing.

Received May 12, 2021

Revised Jun 4, 2021

Accepted Jun 13, 2021

\section{INTRODUCTION}

The substantial decline in the fertility rate has been one of the most significant demographic trends over the last few decades across the developed world [1]. The total fertility rate (TFR) has declined dramatically in most Organization for Economic Cooperation and Development (OECD) countries, from 2.8 children per woman of childbearing age in 1970 to 1.7 in 2016 [2]. This decline is particularly pronounced in South Korea, which has a TFR of 1.05, well below that needed for population replacement. The low TFR might be problematic, as declining fertility rates have negative effects on the ability to ensure the continuance of society and economic growth [3]. The low TFR reflects several societal factors, including an increase in women's education and employment, pursuit of ed- ucational goals, the need to secure economic stability, insufficient social support for childcare, and gender inequality issues [4-6]. South Korea had the highest proportion of women aged 25-34 years with university education among OECD countries in 2017 [7]. Despite increases in educational and employment opportunities, traditional gender roles for women are still prevalent in aspects such as caring for children, with inadequate social support systems and concrete policies to help women achieve their academic and career goals while taking care of children $[5,8]$. In this context, perceptions about the value of family composition, including children, may be negatively affected and impact childbirth planning.

Meanwhile, college students, who are in the early stages of adulthood, form a sense of self-identity in the developmental stage, mature emotionally, and build intimacy with oppo- 
site-sex friends. Therefore, the desire for marriage and/or parenthood also forms in the prospective parent generation [5]. For this reason, a systematic assessment is the first step to encourage positive attitudes towards becoming parents in the prospective parent generation with higher education. However, young men and women's attitudes towards parenthood in South Korea are, at present, relatively unknown.

The Fertility Awareness and Attitudes Towards Parenthood (FAAP) questionnaire was designed for Swedish-speakers in Sweden [9]. This questionnaire was originally developed to assess awareness of fertility and intentions and attitudes towards parenthood among university students. The FAAP questionnaire was shown to have satisfactory face validity and internal consistency (with Cronbach's $\alpha$ values of .75 to .77). This questionnaire has been widely used to measure young adults' knowledge regarding fertility and perceptions of parenthood in various cultural contexts including Sweden [9], the United States [10], and Hong Kong [11]. Since South Korea has the world's lowest birth rate, it might be helpful to use this instrument in young adults to understand their awareness or intentions of parenthood. The FAAP questionnaire consists of seven instruments that assess the following: 1) demographic characteristics, 2) intention to have children, 3) importance of having children, 4) behavioral intention in case of infertility, 5) conditions of importance for the decision to become a parent, 6) perceived life changes in connection with becoming a parent, and 7) awareness of fertility issues.

To our knowledge, there are few instruments that measure parenting perceptions or attitudes in South Korea. In particular, there is currently a lack of validated instruments in Korean for assessing the conditions that young men and women think are important for having children and how they expect their lives to change as a result of having children. Modifying or using an existing instrument with demonstrated satisfactory reliability and validity appears to be a better option rather than developing a new instrument in terms of saving time and money [12]. Therefore, we decided to translate this tool into Korean. The purpose of this study was to translate and culturally adapt the FAAP questionnaire to fit the Korean context and then assess its acceptability, content validity, internal consistency, and construct validity when administered to university students in South Korea.

\section{METHODS}

Ethics statement: This study was approved by the Institutional Review Board of Hallym University (No. HIRB-2019-009) in South Korea. Informed consent was obtained from the participants.
This study used data from a study that investigated fertility awareness, intentions, and attitudes towards parenthood among university students in South Korea [13]. The original data were collected from five universities in South Korea between May and July 2019. The primary purpose of the parent study was to compare intentions and attitudes towards future parenthood and fertility knowledge between male and female university students. For this study, a psychometric evaluation of the FAAP questionnaire was conducted to develop a validated Korean version of the instrument to assess attitudes towards parenthood.

This study involved six steps. In the first five steps, the FAAP questionnaire was translated and culturally adapted from English into Korean, which included forward translation, backward translation, committee review, assessment of content validity, and a pre-test. In the sixth step, a psychometric evaluation including the internal consistency and validity of the Korean version of the FAAP questionnaire was conducted in 166 participants identified through convenience sampling. These processes were conducted based on the internationally accepted and recommended guidelines suggested by Guillemin et al. [12] and the World Health Organization [14].

\section{Instruments}

\section{1) Fertility Awareness and Attitudes Towards Parenthood ques- tionnaire}

In this study, two instruments of the FAAP questionnaire were selected: 1) conditions of importance for the decision to become a parent (FAAP-Conditions) and 2) perceived life changes in connection with becoming a parent (FAAP-Life changes). These two instruments were selected to develop and validate instruments that focus on attitudes towards parenthood in the Korean cultural context. The first instrument, FAAP-Conditions, has 13 items assessing the importance of specific circumstances for the decision to become a mother or father. Respondents rate each item using a 5-point Likert scale from 1 to 5 (from unimportant to very important). The second one, FAAP-Life changes, has 16 items assessing the extent to which participants agree with each item specifying possible consequences of parenthood. Respondents rate each item using a 5-point Likert scale from 1 to 5 (from disagree to entirely agree).

\section{2) Rewards and Costs of Being a Parent}

To assess the criterion validity of the FAAP questionnaire, another Korean instrument, Rewards and Costs of Being a Parent [15], was used. The Rewards and Costs of Being a Parent instrument has 13 items assessing perceived rewards 
and costs of becoming parents in the future. A higher total score indicates a higher recognition of the rewards of being a parent, corresponding to a positive perception of being a parent. The instrument was shown to have satisfactory internal consistency (Cronbach's $\alpha=.80$ ) [15].

\section{Translation and Cultural Adaptation Process}

\section{1) Steps 1 and 2: Forward translation and back translation}

The author of the original FAAP questionnaire granted permission for its use, translation, and cross-cultural adaptation to university students in South Korea. Two bilingual translators whose first language was Korean translated the English version of the FAAP questionnaire into Korean (forward translation). In order to identify and resolve incomplete and vague translations, two translators and the research team members held a consensus meeting. In this meeting, the two translated versions of the questionnaire were compared with the original version, inconsistencies were removed, and a translated version of the FAAP questionnaire was created. Next, two other bilingual translators who had not performed the forward translation translated the FAAP questionnaire in Korean into English (backward translation). The back translators had no information about the original questionnaires and previous processes.

\section{2) Step 3: Committee review}

A committee consisting of three nursing professors and one nursing doctoral student reviewed three versions of the FAAP questionnaire (the version translated into Korean, the version back-translated into English, and the original FAAP questionnaire). All members of the committee were fluent in both Korean and English. The committee members had not participated in either the forward or backward translation process. The committee identified and discussed vague and incomplete translations and removed inconsistencies between the forward translation and the original questionnaire. The appropriateness of the translation was assessed, and semantic, experiential, and conceptual equivalence with the original version were evaluated by the committee.

\section{3) Step 4: Assessment of content validity}

A panel of five experts evaluated the instrument's content validity. This panel consisted of five faculty members at nursing schools who were familiar with the translation process and psychometric evaluation of the instrument. The expert panel rated the relevance of individual items of the two questionnaires, FAAP-Conditions and FAAP-Life changes, to assess the content validity index (CVI) [16]. To determine the item-level content validity index (I-CVI), the expert panel rat- ed the relevance of individual items on a four-point scale ( $1=$ not relevant, $2=$ somewhat relevant, $3=$ quite relevant, and $4=$ highly relevant). The items of the questionnaires were categorized into relevant and irrelevant to obtain the instrument's CVI. The I-CVI was computed by dividing each item score by 5 , which equaled the total number of raters. The CVI for the scale (S-CVI) was computed using the scale level content validity index/average (S-CVI/Ave), as defined by Polit and Beck [17]. For this study, the minimum acceptable criteria were an I-CVI of .78 or above and an S-CVI/Ave of .90 or above [17].

\section{4) Step 5: Pre-test}

The pre-final version of the FAAP questionnaire was administered to 11 university students (six men and five women). University students were eligible to participate if they were: 1) aged between 18 years (based on what majority of countries have suggested as the standard of adulthood) and 30 years (based on data showing that the average age for first marriage was 30.4 years in South Korea) [18], and 2) currently enrolled full-time in a bachelor's degree program at a university. The investigator contacted students who expressed interest in the study after their classes. After providing informed consent, students completed the pre-final Korean version of the FAAP questionnaire in a private room near the classroom. Once completed, we asked students if there were any words or sentences that they found difficult to understand in the FAAP questionnaire. Students' comments were recorded separately by the researcher and attached to the questionnaire.

\section{5) Step 6: Psychometric evaluation}

(1) Participants and data collection

The FAAP questionnaire was translated and cross-culturally adapted from English into Korean and the final Korean version was created. The final Korean version of the FAAP questionnaire was tested among 166 university students. The eligibility criteria for participants were the same as those described above in the pre-testing step. After classes, the research assistant approached the students to assess whether they were able to participate and whether they were interested in the study. Upon providing written consent, students completed the final Korean version of the FAAP questionnaire as well as a socio-demographic survey in a private room.

\section{(2) Data analysis}

The data were analyzed for this study using SPSS version 25 (IBM Corp., Armonk, NY, USA). We used descriptive statistics such as means, standard deviations (SDs), and percentages to describe the participant characteristics. Cronbach's $\alpha$ 
$(\alpha)$ coefficients were calculated to evaluate the internal consistency of the two instruments, FAAP-Conditions and FAAPLife changes. A Cronbach's $\alpha$ higher than .70 was considered acceptable [19].

Two-step factor analysis was conducted to assess construct validity. First, exploratory factor analysis (EFA) using principal component analysis with varimax rotation was used to identify the structure of the Korean version of the FAAP questionnaire and to test the loading strength of the items on factors. Second, confirmatory factor analysis (CFA) with oblimin rotation (maximum likelihood) was carried out using AMOS version 23 to assess how well the structure from the EFA fits the used data. The data suitability for EFA was assessed by the following indices: a value of $\geq .30$ in the correlation matrix, a value of $\geq .60$ in the Kaiser-Meyer-Olkin (KMO) test, and statistical significance $(p<.001)$ in Bartlett's test of sphericity [20]. An eigenvalue greater than 1.0 was used to determine that a factor should be retained, and a factor-loading coefficient of .30 or higher was considered significant. For CFA, the goodness of fit of the data was estimated using the following indicators: $x^{2}$ mean/degree of freedom (CMIN/DF) $\leq 3$, Tucker-Lewis index (TLI) $\geq .90$, incremental fit index (IFI) $\geq .90$, standardized root mean square residual (SRMR) $\leq .08$, comparative fit index (CFI) $\geq .90$, and root mean square error of approximation (RMSEA) $\leq .08$ [21].

Criterion validity was obtained by testing the associations between the Korean instrument, Rewards and Costs of Being a Parent [15], and the FAAP-Conditions and FAAP-Life changes, respectively. The strength of association for $r$ values was interpreted as follows: a negligible correlation $(\mathrm{r}=.00-.10)$, a weak correlation $(\mathrm{r}=.10-.39)$, a moderate correlation $(\mathrm{r}=.40-.69)$, a strong correlation $(\mathrm{r}=.70-.89)$, and a very strong correlation $(\mathrm{r}=.90-1.00)[22]$.

\section{RESULTS}

\section{Steps 1-3: Forward Translation, Backward Translation, and Committee Review}

\section{1) FAAP-Conditions}

Three changes were made in this instrument. In item 9, "That I have access to childcare", the phrase "such as a caring-support facility or caring helper" was added because the concept of "childcare" was considered to be too abstract for university students to understand and respond to without a clarifying example. The phrase "to take care of children" was added in parentheses after item 11 ("That I/we have a home that is sufficiently large") to provide a supplementary explanation of "home that is sufficiently large". Additionally, the term "partner" was replaced with the Korean term "baewooja", which denotes the legal status of a spouse. This replacement was made because students in Korean culture may feel uncomfortable with the direct translation of "partner". Traditionally, it is assumed that parents have children when they are legally married in the Korean cultural context. Thus, the Koreans are more familiar with the term "baewooja" than the term "partner" in this context.

\section{2) FAAP-Life changes}

One change was made for this instrument. Item 7, "Less time for my own interests", was deemed to be too abstract for participants to answer. Thus, a descriptive phrase was added to this item so that it read "less time to enjoy my hobbies and interests".

\section{Step 4: Assessment of Content Validity}

\section{1) FAAP-Conditions}

The I-CVI for this 13-item instrument ranged from .80 to 1.0, and the S-CVI/Ave was .94 from the five raters. Thus, all items were included in the final version of the FAAP questionnaire.

\section{2) FAAP-Life changes}

The I-CVI for this 16-item instrument ranged from .60 to 1.0. One item (item 8) with an I-CVI of .60, "more contact with my close family", was revised before conducting the second validity analysis. The term "family" was replaced with the phrase "close friends and family members" to make it easier for respondents to think about their answers. After revising this item, the CVI analysis yielded values of 1.0 for both I-CVI and S-CVI.

\section{Step 5: Pre-test}

A total of 11 Korean university students were recruited from two universities at the pre-test step. Each participant completed the Korean version of the FAAP questionnaire. During the pre-test, one of the participants reported difficulty in understanding item 12 ("That my friends have had children or are expecting children") of the FAAP-Conditions questionnaire. The researcher provided a supplementary explanation about the item and the student then completed item 12 without difficulty. A discussion was held between the investigator and committee about whether any modification, including different wording and sentence corrections, should be made to item 12. After the discussion, it was finally decided not to revise item 12 . This was because the translation of this item into Korean did not change its original meaning, and no problem was anticipated in terms of general understanding. The 
participants completed the remaining items of the FAAPConditions questionnaire and fully understood them. There were no missing data on any items. The results of the pre-test suggested that Korean university students would easily be able to understand and respond to the pre-final Korean version of the FAAP. As a result, the final Korean version of the FAAP questionnaire was developed.

\section{Step 6: Psychometric Evaluation}

\section{1) Characteristics of participants}

The $\mathrm{M} \pm \mathrm{SD}$ age of participants was $22.3 \pm 1.7$ years (Table 1 ). Approximately half were women $(n=85,51.2 \%)$ and over $70 \%$ of the participants responded that they planned to have children. The $\mathrm{M} \pm S D$ desired number of children was $2.12 \pm 0.70$.

\section{2) Internal consistency}

In the current sample, the Korean version of the two instruments, FAAP-Conditions and FAAP-Life changes, showed acceptable Cronbach's $\alpha$ coefficients ( $\alpha=.73$ for conditions for the decision to become a parent and $\alpha=.83$ for life changes after becoming a parent).

\section{3) Construct validity}

The construct validity verification was conducted in two stages: EFA and CFA. First, the KMO value was .70, and $x^{2}$ was $447.55(p<.001)$ in Bartlett's test of sphericity for the

Table 1. Characteristics of Study Participants $(N=166)$

\begin{tabular}{llc}
\hline Characteristics & Categories & $\mathrm{n}(\%)$ or M \pm SD \\
\hline Year in college* & 2nd & $3(1.9)$ \\
& 3rd & $86(52.4)$ \\
Age (year) & 4 th & $75(45.7)$ \\
Gender & & $22.3 \pm 1.7$ \\
& Male & $81(48.8)$ \\
Living status & Female & $85(51.2)$ \\
& Alone & $49(29.5)$ \\
Relationship status & Family & $75(45.2)$ \\
& Roommate & $42(25.3)$ \\
Length of relationship (month) & Dating & $73(44.0)$ \\
Plan to have children & Single & $93(56.0)$ \\
& Yes & $16.06 \pm 16.64$ \\
Desired number of children* & No & $119(71.7)$ \\
Importance of children & & $47(28.3)$ \\
(total score: 10$)$ & & $2.12 \pm 0.70$ \\
\hline
\end{tabular}

*Missing data were not included;" Values were analyzed from the responses of 119 participants who said they planned to have children.
FAAP-Conditions questionnaire and the $\mathrm{KMO}$ value was .83 and $x^{2}$ was $989.25(p<.001)$ in Bartlett's test of sphericity for the FAAP-Life changes questionnaire. These results indicated that the items of each instrument were suitable for factor analysis. Tables 2 and 3 show the EFA results for the FAAPConditions and FAAP-Life changes, respectively. In the EFA for FAAP-Conditions, four factors with eigenvalues greater than 1.0 were extracted and accounted for $57.51 \%$ of the overall variance (Table 2). The 13 items of the FAAP-Conditions were loaded onto the following four factors: factor 1 (items 6-8), factor 2 (items 1-3), factor 3 (items 4 and 11-13), and factor 4 (items 5,9, and 10). Regarding the dimensionality of the EFA for the FAAP-Life changes, two factors with eigenvalues greater than 1.0 were extracted, and this two-factor model explained 48.58 of the variance (Table 3 ). Factor 1 comprised items $1,3,5,6,8,9,11,13,15$, and 16 and explained $27.15 \%$ of the variance. Factor 2 consisted of items 2, 4, 7, 10, 12, and 14 and accounted for $21.43 \%$ of the variance. As a result, the final 13 items and 16 items were extracted from the two instruments, FAAP-Conditions and FAAP-Life changes, by EFA, and then CFA was conducted. Table 4 and Figure 1 show the results of CFA. The four-factor model of the FAAP-Conditions had adequate data fit, with $\mathrm{CMIN} / \mathrm{DF}=1.64, \mathrm{TLI}=.87, \mathrm{IFI}=.91$, $\mathrm{SRMR}=.07, \mathrm{CFI}=.90$, and RMSEA $=.06$. Although the TLI index was somewhat insufficient, all other values met the standards. All indices of the two-factor model of the FAAP-Life changes met the standards, with $\mathrm{CMIN} / \mathrm{DF}=1.66, \mathrm{TLI}=.91$, $\mathrm{IFI}=.93, \mathrm{SRMR}=.06, \mathrm{CFI}=.93$, and $\mathrm{RMSEA}=.06$.

\section{4) Criterion validity}

The criterion validity of the FAAP-Life changes questionnaire was supported by a strong significant positive correlation with another Korean measure, Rewards and Costs of Being a Parent $(\mathrm{r}=.74, p<.001)$. However, there was no significant relationship between the FAAP-Conditions questionnaire and Rewards and Costs of Being a Parent $(\mathrm{r}=-.01, p=.888)$.

\section{DISCUSSION}

In this study, we described the process of translation and cultural adaptation of the FAAP questionnaire to Korean university students and the validation of its preliminary psychometric properties. The process was conducted in accordance with the widely used and recommended guidelines by Guillemin et al. [12] and the World Health Organization [14]. In addition to word-for-word translations of the questionnaire into Korean, the principle of cross-cultural adaptation was applied in order to maximize its suitability within the Korean context. Additionally, the use of different approaches to psychometric evaluation, including content validity, internal consistency, 
Table 2. Exploratory Factor Analysis of the Korean FAAP-Conditions

\begin{tabular}{|c|c|c|c|c|}
\hline Items & Factor 1 & Factor 2 & Factor 3 & Factor 4 \\
\hline Item 6. That I have completed my studies & 0.77 & & & \\
\hline Item 7 . That I have advanced in my profession & 0.77 & & & \\
\hline Item 8 . That $\mathrm{I}$ have a permanent position & 0.69 & & & \\
\hline Item 1 . That I have a partner with whom I can share the responsibility & & 0.81 & & \\
\hline Item 3. That I live in a stable relationship & & 0.79 & & \\
\hline Item 2 . That I feel sufficiently mature & & 0.58 & & \\
\hline Item 12. That my friends have had children or are expecting children & & & 0.77 & \\
\hline $\begin{array}{l}\text { Item 13. That I have had time to travel and do other things that may be difficult to } \\
\text { do with children }\end{array}$ & & & 0.63 & \\
\hline Item 11 . That I/ we have a home that is sufficiently large & & & 0.58 & \\
\hline Item 4 . That I want to have children before I am 'too old' & & & 0.55 & \\
\hline Item 9. That I have access to childcare & & & & 0.76 \\
\hline Item 10 . That I/we have a good economic situation & & & & 0.69 \\
\hline Item 5 . That my work can be combined with having children & & & & 0.59 \\
\hline Eigenvalue & 1.98 & 1.91 & 1.85 & 1.74 \\
\hline$\%$ of variance explained & 15.19 & 14.67 & 14.26 & 13.39 \\
\hline Cum $\%$ & 15.19 & 29.86 & 44.12 & 57.51 \\
\hline Reliability (Cronbach's $\alpha$ ) & .71 & .62 & .58 & .59 \\
\hline & \multicolumn{4}{|c|}{$\mathrm{KMO}=.70, x^{2}=447.55(p<.001)$} \\
\hline
\end{tabular}

Cum, cumulative; FAAP, Fertility Awareness and Attitudes Towards Parenthood; KMO, Kaiser-Meyer-Olkin.

and construct validity, contributed to the development of adequately valid Korean questionnaires for the measurement of attitudes towards parenthood. Even if a tool has proven reliability and validity, if it is applied to groups with different demographic characteristics and cultures, it is necessary to ensure validity in the translation process and verify reliability and validity in the corresponding population [23]. Validation can be used to verify that the tool is appropriate for the study group and purpose, and whether the concept is actually well measured [24].

The participants completed most of the items in the Korean version of the FAAP questionnaire without difficulty. Additionally, they reported that all items were clearly understood during the pre-test step. In the CVI assessment, no items had an I-CVI of less than .80, and the S-CVI/Ave was above .90 . Accordingly, these findings support acceptable content validity of the Korean FAAP questionnaire. Although the FAAP questionnaire has been widely used in other countries such as Saudi Arabia [25], Sweden [26], and Serbia [27], the previous studies did not report evidence of content validity. The findings of this study demonstrated that the Korean version of the FAAP questionnaire showed acceptable internal consis- tency ( $\alpha=.73$ for FAAP-Conditions and $\alpha=.83$ for FAAP-Life changes), as a Cronbach's $\alpha$ coefficient of at least .70 is typically considered acceptable [19]. Although it is difficult to directly compare these findings with those of other studies, since no other studies have examined these properties, the results of CVI and internal consistency in this study indicated that the Korean FAAP questionnaire was acceptable, easily understood, and could be self-administered among young adults in South Korea.

The EFA analysis in this study revealed that the FAAPConditions and FAAP-Life changes were likely grouped into four and two factors, respectively. The 13 items of the FAAPConditions were loaded on four factors, and these were given the following names by the research team: social conditions (factor 1), relationship with partner (factor 2), external environment (factor 3), and child-rearing support (factor 4). The reason for assigning these names was that factor 1 consisted of items representing employment status and educational attainment (items 6-8) and the items of factor 2 described an individual's relationship with his or her partner (items 1-3), Additionally, the items loaded in factor 3 inquired about the importance of the external environment, such as a home with 
Table 3. Exploratory Factor Analysis of the Korean FAAP-Life Changes

\begin{tabular}{|c|c|c|}
\hline Items & Factor 1 & Factor 2 \\
\hline Item 13. Everyday life will be more enjoyable & 0.76 & \\
\hline Item 6. A stronger relationship with my partner & 0.75 & \\
\hline Item 5 . I will give and receive more love & 0.71 & \\
\hline Item 3. New interests in life & 0.70 & \\
\hline Item 16 . That I do the thing that is the meaning of life & 0.70 & \\
\hline Item 9. That we become a 'real family' & 0.64 & \\
\hline Item 11. Another view on what is important & 0.59 & \\
\hline Item 15. That I feel 'complete' as a woman/man & 0.59 & \\
\hline Item 1 . I will develop as a person & 0.57 & \\
\hline Item 8 . More contact with my close family & 0.48 & \\
\hline Item 12. Less freedom & & 0.81 \\
\hline Item 4 . A poorer status in the labor market & & 0.78 \\
\hline Item 7. Less time for my own interests & & 0.78 \\
\hline Item 14. Poorer economic situation & & 0.72 \\
\hline Item 10. Strains on my relationship with my partner & & 0.67 \\
\hline Item 2. Less time to devote to work and a career & & 0.62 \\
\hline Eigenvalue & 4.34 & 3.43 \\
\hline$\%$ of variance explained & 27.15 & 21.43 \\
\hline Cum\% & 27.15 & 48.58 \\
\hline Reliability (Cronbach's $\alpha$ ) & .85 & .83 \\
\hline \multicolumn{3}{|c|}{$\mathrm{KMO}=.83, x^{2}=989.25(p<.001)$} \\
\hline
\end{tabular}

Cum, cumulative; FAAP, Fertility Awareness and Attitudes Towards Parenthood; KMO, Kaiser-Meyer-Olkin.

Table 4. Confirmatory Factor Analysis of the Korean FAAP-Conditions and FAAP-Life Changes

\begin{tabular}{lcccccccc}
\hline Variables & $x^{2}(p)$ & $\mathrm{df}$ & CMIN/df & TLI & IFI & SRMR & CFI & RMSEA \\
\hline Conditions & $96.50(.001)$ & 59 & 1.64 & .87 & .91 & .07 & .90 & .06 \\
Life changes & $167.63(<.001)$ & 101 & 1.66 & .91 & .93 & .06 & .93 & .06 \\
Standard & & & $\leq 3.00$ & $\geq .90$ & $\geq .90$ & $\leq .08$ & $\geq .90$ & $\leq .08$ \\
\hline
\end{tabular}

CFI, comparative fit index; CMIN/df, $x^{2}$ mean/degree of freedom; df, degree of freedom; FAAP, Fertility Awareness and Attitudes Towards Parenthood; IFI, incremental fit index; RMSEA, root mean square error of approximation; SRMR, standardized root mean square residual; TLI, Tucker-Lewis index.

sufficient space or having close friends who have children (items 4 and 11-13). Lastly, factor 4 had items dealing with the importance of support for child-rearing, such as access to a workplace that provides childcare (items 5,9, and 10). Regarding the FAAP-Life changes, two factors were extracted, and these were given the following names: reward (factor 1) and burden (factor 2). The reason why the research team chose these name was that the items $(1,3,5,6,8,9,11,13,15$, and 16) that made up factor 1 described the positive aspects of being a parent, while the items in factor $2(2,4,7,10,12$, and 14) related to the difficulties or problems that people would face after becoming a parent. It is difficult to directly compare the findings of factor analysis in this study with that of other studies since no other studies have examined construct validity using the same instrument. However, considering the results of CFA, in which the four- and two-factor models had adequate fit indices, the findings suggest that the factor structure gleaned from the EFA fits the data. 
(A)

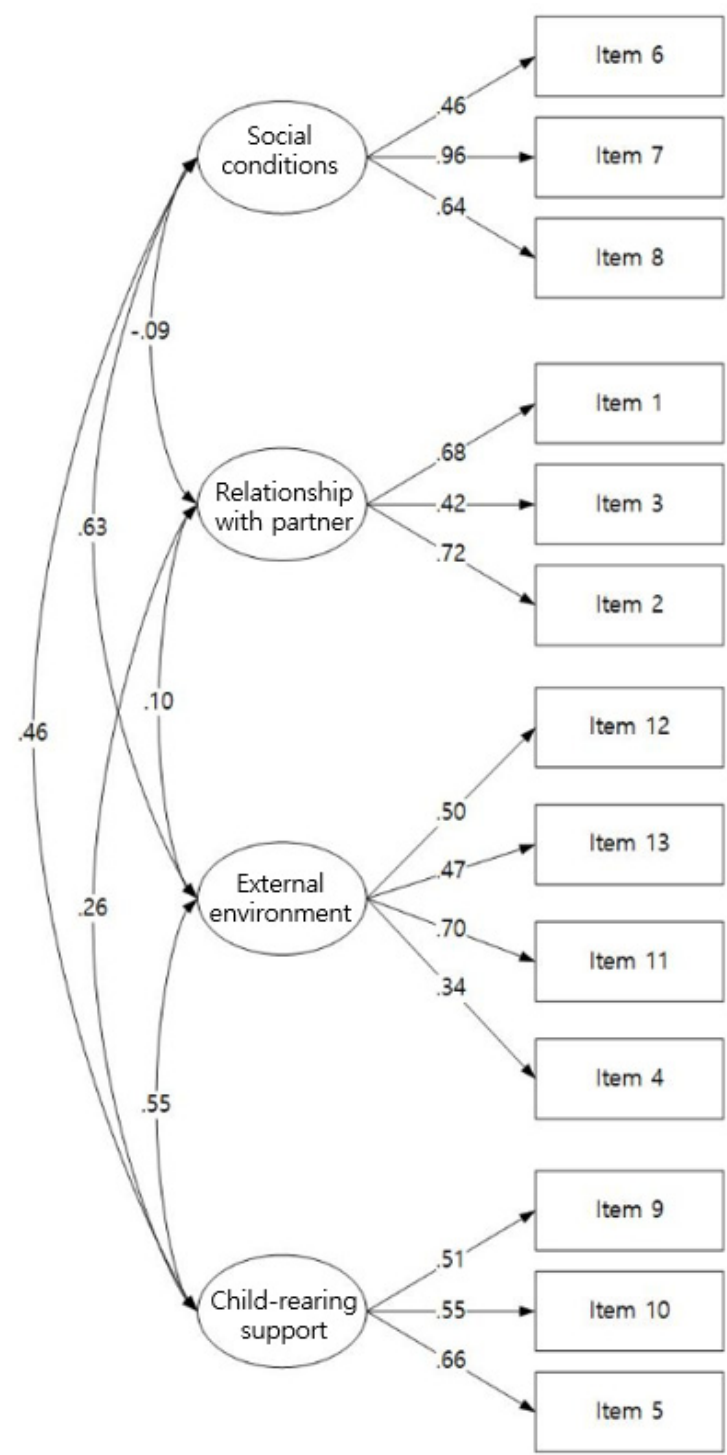

(B)

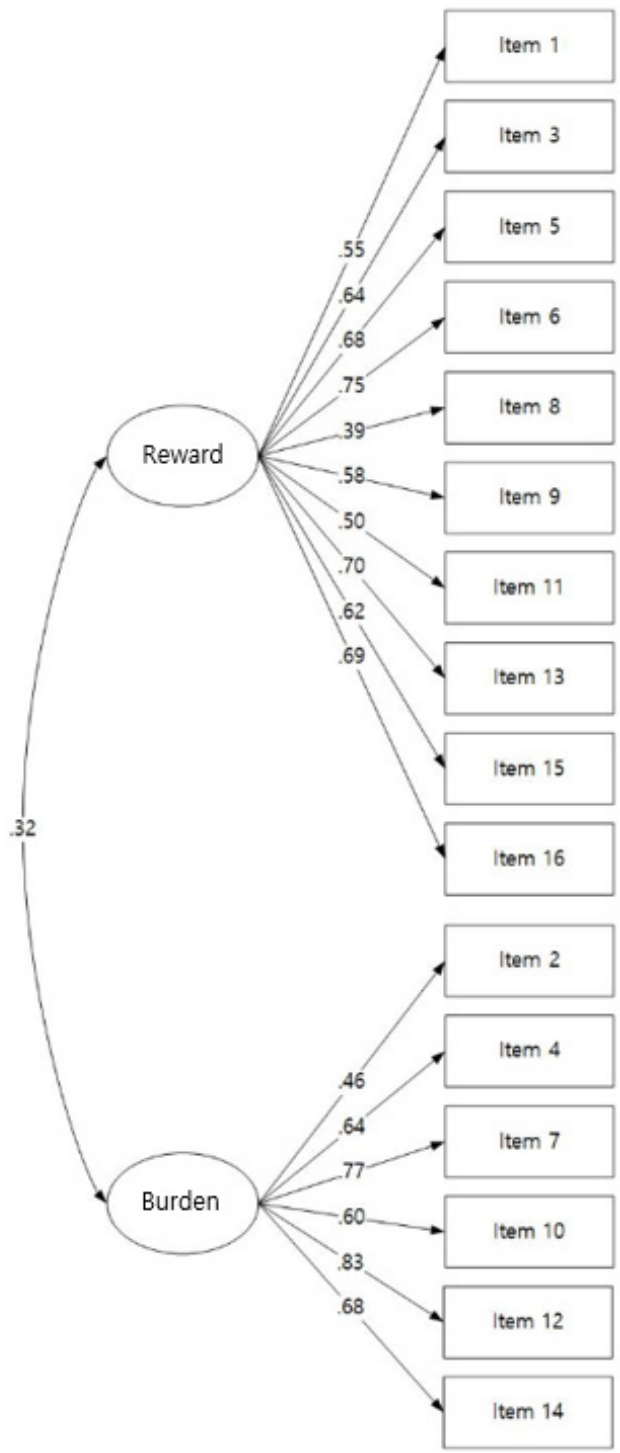

Figure 1. Confirmatory factor analysis of the Korean FAAP. (A) Conditions. (B) Life changes.

Additionally, the Rewards and Costs of Being a Parent instrument [15] was used to test the criterion-related validity with the translated Korean FAAP questionnaire for this study. The findings indicated that only the FAAP-Life changes questionnaire showed a strong correlation with the Rewards and Costs of Being a Parent instrument, whereas the FAAP-Conditions questionnaire showed no significant correlation. These findings are consistent with the researchers' assumption that the FAAP-Life changes would be highly correlated with the Rewards and Costs of Being a Parent instrument, which examines the good and difficult aspects of parenting, confirming the criterion validity of the Korean FAAP questionnaire.

In light of our measurements of the FAAP-Conditions and
FAAP-Life changes, it would be important to provide an educational program. According to a literature review related to the effectiveness of sex education programs for college students, it was effective not to provide sex education focused on simple biological knowledge of sex, but to provide comprehensive sex education that considered biological and social aspects, such as marriage and family formation [28]. In the future, researchers should consider implementing such a comprehensive sex education program so that college students might have time to consider their values and attitudes regarding marriage, family values, and child-rearing. For example, a prior study [29] found that a lecture-based education program lasting one semester in a university setting positively changed 
college students' view of marriage and childrearing.

This study has some limitations. First, the study participants were recruited from urban areas and therefore may not represent all young adults in other areas. In addition, given the increasing trend of the first marriage age (30.4 years old) in South Korea [18], the participants of this study, who were on average in their early 20s, may have been too young to realistically consider being a parent. Additionally, the Korean version of the FAAP-Conditions and FAAP-Life changes should be further assessed for multiple psychometric properties, including stability (test-retest reliability), construct validity (e.g., convergent or divergent), and responsiveness. This is because the results of the study alone are insufficient to determine the validity of the translated questionnaire. Despite such limitations, the results of this study provide preliminary evidence of the reliability and validity of the FAAP questionnaire when administered to young adults in the Korean cultural context. A further evaluation of the questionnaire among Korean young adults in their early to mid-30s (i.e., closer to the average age of marriage) from a more diverse range of areas is warranted to support the findings.

\section{CONCLUSION}

To our knowledge, this is the first study to report the development and psychometric testing of the FAAP questionnaire, which has been widely used to investigate parenthood in various cultural contexts to the younger generation. Overall, the findings in this study suggest that the translated Korean version of the FAAP-Conditions and FAAP-Life changes is a reliable and valid measure of the conditions that young adults think are important to be a parent and how they think their lives will change as a result of having children. Therefore, this instrument may be useful to better understand how young adults perceive parenthood in the Korean cultural context. In addition, the possibility of applying this instrument in other countries where the fertility rate is decreasing as women's social achievement opportunities increase, such as Korea, has important implications. However, further studies in young adults who are closer to the age of marriage and are more seriously considering the possibility of becoming parents is necessary to validate this instrument.

\section{ORCID}

Hyewon Shin

Minjoo Hong

Minjeong Jo

Jungmin Lee https://orcid.org/0000-0003-1831-3710 https:// orcid.org/0000-0002-5013-5531 https:// orcid.org/0000-0002-1101-4008 https://orcid.org/0000-0002-4916-5485

\section{Authors' contribution}

Conceptualization: Hyewon Shin, Minjeong Jo, Jungmin Lee; Data collection: all authors; Formal analysis: Hyewon Shin, Minjoo Hong, Minjeong Jo; Writing-original draft, Writing-review and editing: all authors; Final approval of published version: all authors.

\section{Conflict of interest}

No existing or potential conflict of interest relevant to this article was reported.

\section{Funding}

None.

\section{Data availability}

Please contact the corresponding author for data availability.

\section{Acknowledgements}

None.

\section{REFERENCES}

1. Zeman K, Beaujouan É, Brzozowska Z, Sobotka T. Cohort fertility decline in low fertility countries: Decomposition using parity progression ratios. Demographic Research. 2018;38(25):651-690. https://doi.org/10.4054/DemRes.2018.38.25

2. OECD. Society at a glance 2019: OECD social indicators [Internet]. Paris: OECD; 2019 [cited 2021 March 7]. Available from: https://www.oecd.org/social/society-at-a-glance-19991290.htm

3. Brauner-Otto SR, Geist C. Uncertainty, doubts, and delays: Economic circumstances and childbearing expectations among emerging adults. Journal of Family and Economic Issues. 2018;39(1):88-102.

4. Kim K. The changing role of employment status in marriage formation among young Korean adults. Demographic Research. 2017;36(5):145-172. https://doi.org/10.4054/DemRes.2017.36.5

5 . Lee Y. A study of the parenthood motivation, perceptions of becoming a parent, and confidence about parental roles of university students. Korea Journal of Child Care and Education. 2015;92:1-18.

6. Yoon SY. The influence of a supportive environment for families on women's fertility intentions and behavior in South Korea. Demographic Research. 2017;36(7):227-254. https://doi.org/10.4054/DemRes.2017.36.7

7. OECD. Education at a glance 2018: OECD indicators [Internet]. Paris: OECD; 2018 [cited 2021 March 7]. Available from: https://www.oecd-ilibrary.org/education/education-at-a-glance 
-2018_eag-2018-en

8. World Economic Forum. The global gender gap report 2017 [Internet]. Cologny: World Economic Forum; 2017 [cited 2021 March 7]. Available from:

https://www.weforum.org/reports/the-global-gender-gap-report $-2017$

9. Lampic C, Svanberg AS, Karlström P, Tydén T. Fertility awareness, intentions concerning childbearing, and attitudes towards parenthood among female and male academics. Human Reproduction. 2006;21(2):558-564. https://doi.org/10.1093/humrep/dei367

10. Peterson BD, Pirritano M, Tucker L, Lampic C. Fertility awareness and parenting attitudes among American male and female undergraduate university students. Human Reproduction. 2012;27(5): 1375-1382. https://doi.org/10.1093/humrep/des011

11. Chan $\mathrm{CH}$, Chan $\mathrm{TH}$, Peterson BD, Lampic C, Tam MY. Intentions and attitudes towards parenthood and fertility awareness among Chinese university students in Hong Kong: A comparison with Western samples. Human Reproduction. 2015;30(2):364-372. https://doi.org/10.1093/humrep/deu324

12. Guillemin F, Bombardier C, Beaton D. Cross-cultural adaptation of health-related quality of life measures: Literature review and proposed guidelines. Journal of Clinical Epidemiology. 1993;46(12): 1417-1432. https://doi.org/10.1016/0895-4356(93)90142-n

13. Shin H, Lee J, Kim SJ, Jo M. Attitudes towards parenthood and fertility awareness in female and male university students in South Korea. Child Health Nursing Research. 2020;26(3):329-337. https://doi.org/10.4094/chnr.2020.26.3.329

14. World Health Oragnization. Process of translation and adaptation of instruments [Internet]. Geneva: World Health Oragnization; 2020 [cited 2021 March 7]. Available from:

https://www.who.int/substance_abuse/research_tools/translation /en/

15. Lee SJ. The effects of family strengths and influencing variables on perceptions of parenthood among the university students. Journal of Family Relations. 2009;14(1):243-266.

16. Moule P, Aveyard H, Goodman M. Nursing research: An introduction. 3th ed. New York, NY: Sage; 2016.

17. Polit DF, Beck CT. The content validity index: Are you sure you know what's being reported? Critique and recommendations. Research in Nursing and Health. 2006;29(5):489-497.

https://doi.org/10.1002/nur.20147

18. Statistics Korea. Marriage and divorce statistics in 2018 [Internet].
Daejeon: Statistics Korea; 2019 [cited 2021 March 7]. Available from: http://kostat.go.kr/portal/eng/pressReleases/8/11/index.board

19. Taber KS. The use of Cronbach's $\alpha$ when developing and reporting research instruments in science education. Research in Science Education. 2018;48:1273-1296.

https://doi.org/10.1007/s11165-016-9602-2

20. Watkins MW. Exploratory factor analysis: A guide to best practice. Journal of Black Psychology. 2018;44(3):219-246. https://doi.org/10.1177/0095798418771807

21. Moon SB. Basic concepts and applications of structural equation modeling with AMOS 17.0. Seoul: Hakjisa; 2009. p. 383-458.

22. Schober P, Boer C, Schwarte LA. Correlation coefficients: Appropriate use and interpretation. Anesthesia and Analgesia. 2018;126(5): 1763-1768. https://doi.org/10.1213/ANE.0000000000002864

23. Lee EO, Lim NY, Park HA, Lee IS, Kim JI, Bae JY, et al. Nursing research and statistical analysis. 4th ed. Paju: Soomoonsa; 2009.

24. Grove SK, Burns N, Gray J. The practice of nursing research: Appraisal, synthesis, and generation of evidence. 7 th ed. Amsterdam: Elsevier Health Sciences; 2012.

25. Alfaraj S, Aleraij S, Morad S, Alomar N, Rajih HA, Alhussain H, et al. Fertility awareness, intentions concerning childbearing, and attitudes toward parenthood among female health professions students in Saudi Arabia. International Journal of Health Sciences. 2019;13(3):34-39.

26. Sørensen NO, Marcussen S, Backhausen MG, Juhl M, Schmidt L, Tydén $\mathrm{T}$, et al. Fertility awareness and attitudes towards parenthood among Danish university college students. Reproductive Health. 2016;13:146. https://doi.org/10.1186/s12978-016-0258-1

27. Vujčić I, Radičević T, Dubljanin E, Maksimović N, Grujičić S. Serbian medical students' fertility awareness and attitudes towards future parenthood. European Journal of Contraception and Reproductive Health Care. 2017;22(4):291-297.

https://doi.org/10.1080/13625187.2017.1368478

28. Shin H, Lee JM, Min HY. An integrative literature review on sex education programs for Korean college students. Journal of Korean Academic Society of Nursing Education. 2020;26(1):78-96. https://doi.org/10.5977/jkasne.2020.26.1.78

29. Choi IS. Effect of pre-parent education program on the view of marriage and the parenting attitude of college students. Asia-pacific Journal of Multimedia Services Convergent with Art, Humanities, and Sociology. 2019;9(1):795-804.

https://doi.org/10.35873/ajmahs.2019.9.1.079 